\title{
Quality of Life in Cancer Patients- A Nursing Perspective
}

\section{Maria Lavdaniti*}

Nursing Department, Alexander Technological Educational Institute of Thessaloniki, Greece

*Corresponding author: Maria Lavdaniti, Assistant Professor, Nursing Department, Alexander Technological Educational Institute of Thessaloniki, Greece; Tel: +0306937865660; E-mail: maria_lavdaniti@yahoo.gr

Received date: Mar 26, 2015, Accepted date: Apr 1, 2015, Published date: Apr8, 2015

Copyright: @ 2015 Lavdaniti M. This is an open-access article distributed under the terms of the Creative Commons Attribution License, which permits unrestricted use, distribution, and reproduction in any medium, provided the original author and source are credited.

\section{Editorial}

Cancer is the second leading global cause of death. According to the World Health Organization, "there were 14.1 million new cancer cases and 8.2 million people living with cancer in 2012 worldwide." [1].

Quality of life is defined as "an individual perception of their position in life in the context of the culture and value systems in which they live and in relation to their goals, expectations, standards and concerns" [2,3]. Both the terms 'quality of life' and 'health-related quality of life' relate to physical, psychological and social aspects of health [4].

Cancer and its treatment cause many complications with a detrimental effect on quality of life and a significant influence on health-related quality of life (HRQOL) in general [5]. As can be seen from the literature review, quality of life is an issue investigated by many researchers, some of whom have done so during chemotherapy [6], radiotherapy and other treatments, such bone marrow transplants [7]. Others referred to quality of life in specific types of cancer (breast, lung, prostate) [8]. Recently, research has been published on quality of life in spouses of breast cancer patients [4]. The aforementioned studies indicated that quality of life is an important consideration when delivering care to cancer patients. The above reports are consistent with Heydarnejad's statement that "an increasingly important issue in oncology is to evaluate quality of life in cancer patients" [9].

Many instruments can be used to measure quality of life in cancer patients. They are divided into three categories: generic instruments, cancer specific and domain specific instruments [10]. Also, there are further instruments which can be applied when assessing children and adolescents, patients or families [10] or cancer survivors [11]. Some of the most popular cancer specific instruments are the EORTC Core Quality of Life Questionnaire (EORTC QLQ C-30), Functional Assessment Cancer Therapy General (FACT-G), the Functional Living Index Cancer (FLIC) and the Cancer Rehabilitation Evaluation System (CARES-SF) [10].

This evokes a question with respect to nursing and quality of life in cancer patients: How can nurses alleviate patients' symptoms and improve their quality of life? First of all, nurses must assess quality of life. Since patient education is critical, nurses should discuss potential impairment of quality of life with patients during their initial visit. Moreover, they must consider factors influencing quality of life, such as culture, age, diagnosis, environment, personal or social issue, as well as other factors, for instance fatigue, pain, lack of sleep, demographicand disease-related factors and self-efficacy [12].

Nurses should help patients to manage the side of effects of therapy and cope with body image changes and other changes in functional living and appearance. Also, they can influence certain 'environmental' factors and provide information to patients and family members with respect to symptoms management and personal or social issues [12]. Evidence revealed non-invasive interventions such counselling, psychotherapeutic, psychosocial and educational interventions. These measures can play a role in improving patients' quality of life [13].

In my opinion, quality of life is an important aspect of nursing care in clinical setting with oncology patients. As a concept, it fits in well with nursing goals. Nurses must assess patients and their caregivers and plan their care based on their needs. As nursing trainers, we must teach our students that cancer is a chronic illness affecting all dimensions of the human being, and hence quality of life as well. One of our goals is the improvement of quality of life, because with this way nurses can help patients to achieve rehabilitation or accompany them as they move toward a peaceful death. Finally, let us stress that although the issue of quality of life is well documented, there is still a need to develop interventions which offer support to patients and their families.

\section{References}

1. GLOBOCAN 2012 Estimated Cancer Incidence, Mortality and Prevelance worldwide in 2012.

2. [No authors listed] (1998) The World Health Organization Quality of Life Assessment (WHOQOL): development and general psychometric properties. Soc Sci Med 46: 1569-1585.

3. Tsitsis N, Lavdaniti M (2014) Quality of Life in Women with Breast Cancer. Int J Caring Sc 7: 38-42

4. Shor V, Grinstein-Cohen O, Reinshtein J, Liberman O, Delbar V (2015) Health-related quality of life and sense of coherence among partners of women with breast cancer in Israel. Eur J Oncol Nurs 19: 18-22.

5. Johansson B, Brandberg Y, Hellbom M, Persson C, Petersson LM, et al. (2008) Health-related quality of life and distress in cancer patients: results from a large randomised study. Br J Cancer 99: 1975-1983.

6. Baczewska B, Kaminska M, Ciszewski T, Kubiatowski T, MakaraStudzinska M, et al. (2014) Quality of life and occurrence of depression under chemotherapy in patients suffering from lung carcinoma. Ann Agric Environ Med 21: 783-789.

7. Andrykowski MA, Bishop MM, Hahn EA, Cella DF, Beaumont JL, et al. (2005) Long-term health-related quality of life, growth, and spiritual wellbeing after hematopoietic stem-cell transplantation. J Clin Oncol 23: 599-608.

8. Lavdaniti M, Tsitsis N, Chrysomallis M (2014) Quality of life in lung cancer patients. Proceedings of 1 st International Balkan Conference on Health Sciences. p.86 Edirne, Turkey

9. Heydarnejad MS, Hassanpour DA, Solati DK (2011) Factors affecting quality of life in cancer patients undergoing chemotherapy. Afr Health Sci 11: 266-270.

10. Adamakidou Th, Kalokerinou A (2012) Quality of Life and cancer patient (Part II): instruments for its assessments. BMMR 15: 47-62

11. Avis NE, Smith KW, McGraw S, Smith RG, Petronis VM, et al. (2005) Assessing quality of life in adult cancer survivors (QLACS). Qual Life Res 14: 1007-1023. 
Citation: Maria Lavdaniti (2015) Quality of Life in Cancer Patients- A Nursing Perspective . J Nurs Care 4: e126. doi: $10.4172 / 2167-1168.1000 \mathrm{e} 126$

Page 2 of 2

12. Grant MM, River LM (2003) Evolution of quality of life in oncology and oncology nursing. In King CR \& Hinds PS (eds). Quality of life: From nursing and patient perspectives. Theory-Research-Practice. Jones and Bartlett Publishers. Sudbury Massachusetts.
13. Rueda JR, Solà I, Pascual A, Subirana Casacuberta M (2011) Non-invasive interventions for improving well-being and quality of life in patients with lung cancer. Cochrane Database Syst Rev 7: CD004282. 